\title{
Peer Production, the Commons, and the Future of the Firm
}

\section{Citation}

Yochai Benkler, Peer Production, the Commons, and the Future of the Firm, 15 Strategic Org. 264 (2017).

\section{Permanent link}

http://nrs.harvard.edu/urn-3:HUL.InstRepos:37078633

\section{Terms of Use}

This article was downloaded from Harvard University's DASH repository, and is made available under the terms and conditions applicable to Other Posted Material, as set forth at http:// nrs.harvard.edu/urn-3:HUL.InstRepos:dash.current.terms-of-use\#LAA

\section{Share Your Story}

The Harvard community has made this article openly available.

Please share how this access benefits you. Submit a story.

\section{Accessibility}




\section{Peer production, the commons, and the future of the firm}

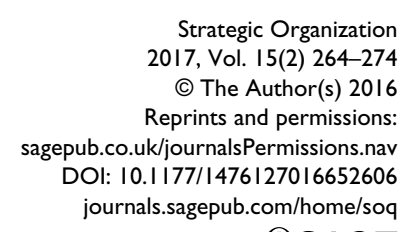

Strategic Organization 017, Vol. I5(2) 264-274 C) The Author(s) 2016 Reprints and permissions: DOI: $10.1177 / 1476127016652606$ @SAGE

\author{
Yochai Benkler \\ Harvard Law School, USA
}

\begin{abstract}
From free and open source software, through Wikipedia to video journalism, peer production plays a more significant role in the information production environment than was theoretically admissible by any economic model of motivation and organization that prevailed at the turn of the millennium. Its sustained success for a quarter of a century forces us to reevaluate three core assumptions of the standard models of innovation and production. First, it places intrinsic and social motivations, rather than material incentives, at the core of innovation, and hence growth. Second, it challenges the centrality of property, as opposed to the interaction of property and commons, to growth. And third, it questions the continued centrality of firms to the innovation process.
\end{abstract}

\title{
Keywords
}

design and boundaries, knowledge creation, organizational structure, social networks, technology, transaction cost economics

Peer production is the most theoretically radical organizational innovation that has emerged from Internet-mediated social practice. Any economist who would have predicted in 1996 that a group of developers working on webserver software, using no formal managerial hierarchy and relying on a copyright license that gave no one exclusive proprietary control over the products of the collaboration would beat Microsoft in a market that was core to Microsoft's Internet strategy would have been laughed out of the room. And yet Apache beat Microsoft Server over the past twenty years, and its fastest growing competitor is Nginx, another free or open source software (FOSS) project. From FOSS through Wikipedia to video journalism, peer production plays a more significant role in the information production environment than was theoretically admissible, much less predicted, by any economic model of motivation and organization that prevailed at the turn of the millennium. Its sustained success for a quarter of a century forces us to reevaluate three core assumptions of the standard models of innovation and production. First, it places intrinsic and social motivations, rather than material incentives, at the core of innovation, and hence growth. Second, it challenges the 
centrality of property, as opposed to the interaction of property and commons, to growth. And third, it questions the continued centrality of firms to the innovation process.

Classic theories of the firm are under severe pressure from collapsing transactions costs and the increasing strategic importance of incontractible aspects of innovation and problem solving. Peer production and open innovation more generally, flash teams, online labor markets for high- and low-skills, and the increasing degree to which problem-solving and innovation under uncertainty are central to growth questions the continued necessity of firms. Considered through the older theoretical lenses, classic firms appear destined to shrink towards playing niche roles where highly concentrated capital requirements persist and cannot be displaced by networks; or where obtaining and managing government-granted rent-extraction opportunities, like patents, are salient. To thrive beyond these confines, firms will have to reorient their strategy to assure a persistent, unique knowledge-based advantage. The organizational attributes of peer production suggest that this reorientation will require firms to emphasize cooperative continuity, which combines motivational diversity - the ability to harness and combine diverse motivations of talented individuals, managing the delicate balance between intrinsic and pro-social motivations and material interests, and social integrity - offering a shared identity and social meaning that keeps teams as persistent learning networks with long-term direct and indirect reciprocity and mutual social recognition.

Organizationally, peer production combines three core characteristics: (a) decentralization of conception and execution of problems and solutions, (b) harnessing diverse motivations, and (c) separation of governance and management from property and contract. The latter two elements in particular challenged received wisdom in economics. While peer production shares several attributes with the broader range of open and distributed innovation practices motivating this special issue, and which offer firms substantial choices and practical challenges as they manage their boundary in relations to this range of choices (Lakhani et al., 2013), here I emphasize the theoretical challenges implications offered by the full package of peer-production. In particular, I suggest a combination of transactions cost economics and the implications of tacit knowledge to explain the most distinct characteristics: the reliance on commons for governance, the centrality of nonmonetary motivations, and the permeation of firm boundaries.

Much of the early economic analysis of peer production focused on software (Bessen, 2006; Ghosh, 1998; Lerner and Tirole, 2002), but FOSS was understood by some from the start as an aspect of online cooperation generally (Ghosh, 1998; Kollock, 1999; Moglen, 1999). Of particular relevance was work that focused on the comparative advantages of peer production as an organizational and institutional model of collaborative innovation and information production in bringing diverse individuals to bear on a problem, using diverse motivations, unencumbered by constraints imposed by property or managerial hierarchy. (Benkler, 2002; Von Hippel and Von Krogh, 2003; on the actual diversity of motivations in FOSS see David and Shapiro, 2008; Lakhani and Wolf, 2005). The basic transactions costs theory of the firm (Coase, 1937; Williamson, 1985) offered the foundation for the simplest transactions costs of peer production. When technology dropped the cost of communications, distributed the material capital necessary for knowledge work throughout a large population, and allowed individuals to share designs and incremental improvements with each other, these individuals were able to pool their knowledge and resources, and coordinate action toward shared goals, without the mediation of firm hierarchies or markets (Baldwin and Von Hippel, 2010; Benkler, 2002). Innovations dependent on high capital costs continued to be produced within firms, but otherwise the change in transactions costs opened the door to an alternative organizational form.

Transactions cost theory alone does not, however, explain the rise of non-monetary motivations for many of the most successful distributed innovation projects, or the successful separation of contract and property from governance in the most prominent success stories. MTurk or Uber are 
equally a product of the reduction of transactions costs as peer production, where market signals harness well-defined material motivations to provide work through more efficient markets. Crowdsourcing like MTurk is incapable of producing innovation, however, instead using the low transactions costs to harnesses simple human labor applied to well-defined tasks. Distinguishing MTurk from FOSS as an organizational model cannot, therefore, depend on a transactions costs theory. It requires a theory of knowledge production and learning as well. In this, peer production shares the core insight of open innovation, user innovation (Von Hippel, 1988, 2005), sociological research on innovation networks (Powell, 1990, 1996) and innovation clusters (Gilson, 1999; Saxenian, 2000), and even broader work on the commons (Ostrom, 1990).

Innovation is a collective, not individual process. It is a process of learning, and therefore depends crucially on communication. Because there is a gap between the depth and extent of communications and connections within the human brain and the communications between human beings through language, the process of knowledge production and learning is always lossy. Knowledge is always at least partly tacit. It is therefore sticky, local, and social. No matter how detailed a memo a twenty-five year veteran of a firm will leave her successor, the successor will not have the same knowledge of the firm's dynamics as the retiring veteran. von Hippel's work on user innovation is the easiest example to grasp. Over decades, von Hippel and others have shown that the diversity of challenges and requirements presented to users in the real world are too diverse to justify firms investing in solutions. As a result, users solve problems and innovate, and only after a class of uses and solutions is defined do firms enter to "productize" the solution, once its characteristics are reasonably well-defined. But similar dynamics that make pricing and managing innovation and knowledge work difficult are present in academic-market collaborations, in open innovation, and in peer-production.

Because knowledge is tacit, it is difficult to elicit fully with property or contract mechanism, and with hard economic incentives. Processes necessary to standardize knowledge and insight into packets that can be traded in markets or fully supervised in firms are "lossy": they lose information about the nature of the problem to be solved, the individual and inter-personal attributes that make a particular solution to the problem best executed by this particular team or that, along these particular lines or those, etc. Commons, by contrast, are better at eliciting non-monetary motivations, both intrinsic and extrinsic-social, like status. This is due to the well-documented phenomenon of motivation crowding out (Bowles and Hwang, 2008; Bowles and Polanía-Reyes, 2012). Intrinsic and social motivations are powerful, but unlike extrinsic motivations, particularly monetary incentives, do not require the explicit accounting that makes market- and hierarchy-based mechanisms lossy. By "commons" I mean a family of institutional mechanisms that eschews exclusive control over property, and utilizes a diverse range of social governance mechanisms to manage the utilization of resources and projects other than property and contract (for a review of the relationship between the literature following Ostrom, 1990 and the work on Internet commons, cultural commons, etc. see Benkler, 2013). Our experience with FOSS success in enabling collaboration among paid and unpaid contributors to commons-based innovation suggests that combining the two is not impossible, but it is quite clear that doing so requires a separation between property and contract that enable the payment on the one hand, and the governance of the project on the other hand. It also requires substantial investment in community management and understanding the social processes of the commons-based community, an investment quite distinct from the investment necessary for managing a price-mediated or hierarchically-organized enterprise.

As a result, organizations, communities, or networks of actors of diverse forms aiming to pursue innovation are faced with several tradeoffs in how to organize and manage their efforts. The more routine the tasks involved in the process, and the more fungible the knowledge and skills necessary for the tasks are, the more appropriate standard "incentives" are to motivating contributions, and 
the more complete a role market-based incentives can play in eliciting effort. The more knowledge intensive, creative, and complex the problem is, the more lossy these hard incentives will be, and the more important it will be to use a form that elicits diverse pro-social motivations. This tradeoff mirrors the tension between firms' focus on efficiency and exploitation of existing knowledge and their capacity to pursue exploratory innovation (Benner and Tushman, 2003). But when considering innovation as a broad social system, as opposed to the internal tensions within an organization, it emphasizes the systemic tensions between models of organization whose comparative advantage is in exploitation and efficiency, and those whose advantage is in exploration and experimentation. In its most familiar form, this understanding explains the comparative roles of academic science relative to commercial R\&D. Similarly, the more uncertain the project space, or the answer to the question "what shall we do"? "where shall we search for a solution?" the more important exploration of a possibility space, low-cost experimentation across a wide range of opportunities and diversity of knowledge-carrying contributors applying themselves to the question is. Hence the importance of user innovation in spaces that solve as-yet unknown needs. By contrast, the betterunderstood a space is, the more a firm can focus on optimization-in von-Hippel's framework, the firm can "productize" the outputs of user innovation, or in the case of FOSS, firms can focus on implementing and services that optimize the space developed in a free software community. Institutionally, that means that as knowledge development and production are more important, in a space that is at the outer frontier of knowledge and problem-solving, the more important it is to adopt an institutional framework that assures freedom to operate, a commons, whereas the more certain and understood the problem space is, the more firms in the space can focus on appropriation of the fruits of investment. All these factors are, as discussed above, constrained by capital cost and communications cost, and are limited to those instances where capital costs are sufficiently low, or capital investment sufficiently widespread in the population (as with personal computers), to permit a distributed, commons-based strategy to operate effectively at a scale appropriate to the problem at hand. Figure 1 maps various open innovation and peer production strategies on a threedimensional space. The $\mathrm{X}$ axis defines the degree of uncertainty associated with the question of what project any group of people, firm or otherwise, should pursue given opportunities and capabilities available, where the origin defines well-understood opportunities, and uncertainty increases away from the origin. The $\mathrm{Y}$ axis defines the human resources necessary for a project. At the origin, the skills, knowledge, and insights needed to pursue a project are routine and well defined, and the axis moves toward states in which the human resources necessary are more knowledge intensive, tacit, creative, diverse, and hard to standardize. The $\mathrm{Z}$ axis describes the material capital necessary for effective production of a given project, where near the origin the capital investment necessary is high and concentrated, and the axis moves our toward situations where effective production by a given group of people, on a given set of project, can be pursued with low capital investment or with capital investment that is distributed in the hands of potential contributors to the project. The three dimensional space offers an initial explanation of the mixed approaches we have in fact seen develop in our knowledge production system, and perhaps explains the highly-visible role that commons-based peer-production has had during the turbulent, fast-moving first three decades of Internet innovation.

This framework also allows us to place many other observed practices of the past decades.

Crowdsourcing (Howe, 2006) is the phenomenon most often confounded with peer production, whose clearest instance is Amazon Mechanical Turk (MTurk). It is distinct from peer production because the tasks it involves are narrowly pre-specified by the task designer. It leverages the same transactions costs reduction features, but only those, and does not leverage the knowledge-production characteristics of peer production that make diverse motivations and collaboration central. The critical distinction between crowdsourcing and peer production is in the location of conception of 


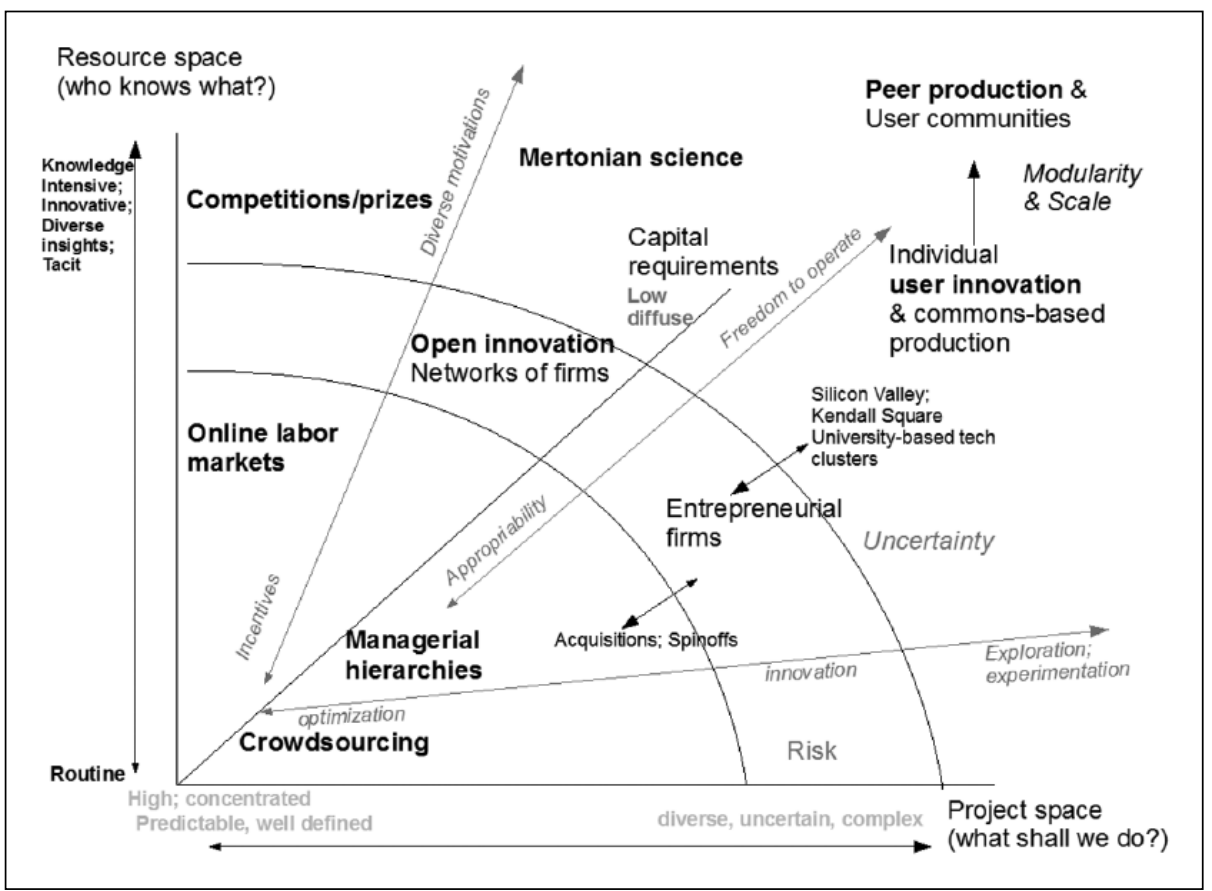

Figure I. Three-dimensional map of open innovation and peer production strategies.

tasks and solutions. It described situations where the task is conceived and defined by a given entity, and then put out to distributed individuals whose actions are limited to performing the preconceived task. It harnesses undifferentiated human labor, rather than the diversity of judgment, creativity, experience, tacit knowledge, or talent. From an organizational perspective, crowdsourcing represents a relatively small innovation. It harnesses thousands of independent contractors to perform pre-specified tasks; but does not affect governance or ownership, restructure innovation or learning, or generally harness any new motivational vectors. As a strategic matter, "crowdsourcing" is relevant where cost-reduction, rather than distributed exploration and innovation, is the goal, and technology does not allow capital investment to replace labor.

Online labor markets use the low transactions costs associated with online knowledge work to allow firms to harness distributed talent from around the world. Upwork at the high end or TaskRabbit at the lower end are well known examples. They represent a significant improvement in the efficiency of markets for skilled and unskilled labor, but do not shift conception from the buying firm to the external expert. They challenge the continued role of firms from a transactions costs perspective, but they do not present a clear alternative for innovation strategy.

Prize systems like TopCoder, Innocentive, or Kaggle, provide platforms for general purpose or field-specific competition and prize systems to be deployed to harness creative problem solving effort towards problems posed by firms or governments. Unlike online labor markets, they emphasize decentralization of conception and execution, leaving task design to a distributed pool of innovative, skilled workers and entities. Because prize systems pay for outcomes, not effort, from the firm's perspective they afford wider and more diverse experimentation with alternative solution approaches than online labor markets. This, in turn, allows them to capture extreme value solutions in areas where the problem definition and path of execution are highly uncertain. (Boudreau et al., 
2011). However, they do this by externalizing the costs of experimentation to the participants, harnessing distributed knowledge and expertise in a relatively wasteful model for non-winning efforts. Because of the status framing of "prizes," they also sometimes harness non-monetary, particularly status-oriented, contributions. While defining a prize system still requires quite explicit and complex definition of what success or failure entails (Burstein and Murray, 2016), it nonetheless is able to harness efforts that are not constrained toward definitions sufficiently crisp for pricing or managerial command.

Open collaborative innovation, by contrast with these online models, is the least dependent on changes in transactions costs. It reflects instead changes in theories of knowledge production and problem solving. These practices developed among firms in various complex product and innovation-rich markets for a while, although they have gotten a boost from networked communications (Chesborough, 2003; Gilson et al., 2008, 2010; Powell, 1990, 1996). They can be complements or substitutes for peer production, depending on the degree of control a firm wishes to exercise over the solution developed. A firm facing a complex software development problem could enter into relational contracts with several of its suppliers or even competitors, adopt open standards at the core of its strategy, and place some of its workers in other firms and receive those of others in its own as part of an open collaborative strategy. In the alternative, that same firm could partly develop the software it requires and license it as FOSS and use Sourceforge or GitHub to manage the repository. In the former case, the firm would be engaged in open collaborative innovation. The latter would be the firm engaging peer production. Open collaborative innovation shares with peer production the recognition that the best people to solve a given problem are unlikely to work for the firm facing the problem, and that models of innovation that allow diverse people, from diverse settings, to work collaboratively on the problem will lead to better outcomes than production models that enforce strict boundaries at the edge of the firm that undermine collaboration based on fit of person to task rather than based on employment contract and ownership of resources associated with the problem. These overlaps in the theory of knowledge production create strong overlaps between open collaborative innovation and peer production from policy perspectives, primarily in implications for intellectual property. But because this category does not include the separation of ownership from governance and management, it limits participants to those who are part of a set of mutually-cooperating firms, and does not necessarily leverage non-monetary motivations. It trades off manageability and appropriability for diversity and search space. Interestingly, this framework also helps to explain the dynamics of Silicon Valley or Kendall Square - the town-gown collaborations - as well as the relatively informal culture, the strong emphasis during the period of high innovation rates in the first thirty years of Internet innovation on growth not revenue, and the strong cultural shifts to accepting and embracing failure among entrepreneurs. All these features of start-up culture in the United States and Israel in particular contribute to looser accountability and high degrees of low-cost experimentation driven by mixed motivations.

While peer production is developing into a field in its own right, its implications for economics and organization theory are broader than the phenomenon itself. These include the uncertain future of the firm, the integration of intrinsic and prosocial motivations into models of human behavior, and the integration of open commons into our understanding of growth.

Coase's theory of the firm was based on transactions costs. Because transactions costs existed, firms developed and grew up to the point where the cost of allocating resources to projects through managerial hierarchies exceeded the cost of doing so in the market. Williamson's adaptation added monitoring of agents who acted under self-interest with guile. When transactions costs are moreor-less eliminated, technology for monitoring every keystroke and contribution is ubiquitous, and innovation depends as much on prosocial and intrinsic motivations as on extrinsic motivations appropriate for agents who act under self-interest with guile, what role, if any, remains for the firm? 
The decline in transactions costs puts severe pressure on the need for a firm. Online labor markets like Upwork offer early examples of spot markets for high talent where a firm is trying to manage projects that require more diverse knowledge than its present employees possess. A more ambitious version suggests the possibility of developing a more general organizational strategy in the form of flash teams: teams of experts who can assemble for a given task, and then disassemble and move on to other tasks. (Retelny et al., 2014). On-demand economy sites like Uber or TaskRabbit suggest that the model of market clearance of routine labor from end consumers to workers is also becoming very low friction, and information systems are replacing managerial control for monitoring and quality control. These most recent developments are examples of market transactions displacing what would once have been the function of a firm-collecting, vetting, and training a team, and then managing it through completion of a task, and delivery to a customer. Both Upwork and more routine on demand labor platforms are primarily extensions of existing models of independent contracting, improved by the dramatic reduction in transactions costs. A decade ago, John Seely Brown and John Hagel (2005) emphasized that the ability to orchestrate "creation nets" was "the only sustainable edge". At the time, the orchestration still focused on orchestrating firms in global supply chains anchored in open innovation as collaboration among firms, small and large. But as online labor markets combine with peer production to make conceivable, if not force, a fluid global market in labor and talent, the question runs much deeper. What continues to be the role of the firm where transactions costs are low enough to allow "orchestration" of networks of resources to be the sole remaining function of a firm? And if talent pools and knowledge resources can be orchestrated for particular projects, why is orchestration itself not a role that can be fluid and ad hoc?

One possible answer is that firms will remain significant only where physical capital costs of production are high and concentrated. Even this limitation, however, may be less limiting that it first appears. Current experience with semi-conductor foundries suggests that very high capital costs lead to concentration of manufacturing, while still leaving of $R \& D$, patenting, and branding in the hands of other firms. This is largely the relationship between a foundry like TSMC and Qualcomm. The question, from the perspective of the theory of the firm, is what role will Qualcomm continue to play, even if TSMC's role in continuing to optimize high-capital-cost production is safe? The answer may be that the cost of prosecuting and licensing patents, or managing demand through control of brands is sufficient to justify keeping R\&D and intellectual property within a single legal boundary of a firm, but it is far from clear at a theoretical level what advantage such a legal monopoly-based firm would have, from the innovation perspective, over a flash team that rapidly designs the next generation chip, and then uses the foundry to capture the rents through first mover advantage without incurring these larger costs. One option for answering the question about the future of the firm, then, is that firms will continue to play a role (a) when they have the advantage in amortizing high capital costs over many diverse innovation efforts where optimization of that innovation and its manufacture and distribution are core necessities (this is the direct implication of Figure 1), or (b) when exploiting legally-created rent extraction opportunities gives an advantage to a continuous legal entity such as a firm over a more fluid market relationship that comes together purely for the purposes of exploration and innovation. This creates the possibility of multiple equilibria, where legal regimes that open the possibility for commons-based production elicit innovation that does not need regulatory protection and the rents it enables, and that moves rapidly outside of the boundary of firms, while legal regimes that do create rent-extraction opportunities create firms to develop innovation along lines optimized to capture those rents, and further invest in securing the rentextraction institutional devices. The continued role of firms in innovation, in this context, becomes contingent and path dependent, rather than efficiency- or growth-optimizing in a social welfare sense. (For one evolutionary model along these lines see Landini (2012)). 
Another possible answer about the future of the firm comes from the second implication of peer production - the centrality of pro-social and intrinsic motivations. Parallel to Williamson's concept of monitoring, a firm that is particularly good at creating a culture that will be better at eliciting and focusing pro-social and intrinsic motivations on a given class of projects than a loose network of peers will have an important and persistent role to play. If "absorptive capacity" as a concept implied a stable boundary of the firm, and learning inside the firm that allowed its internal players to understand and take advantage of externally developing innovation, then we could think of "cooperative capacity" as the idea that a firm could maintain its coherence in the face of vanishing transactions costs if it is able to harness diversely motivated individuals to work in a persistent social relationship. Motivational diversity overcomes the problems of contractibility and monitoring, while social integrity permits sufficient interaction and learning feedbacks over time for knowledge to emerge within the networks of people who are part of the firm that is unique relative to knowledge outside the boundary of the firm, knowledge that gives the firm its distinct advantage over ad hoc networks of innovation and production. Theoretical frameworks like shareholder value or agency theory strove to achieve efficiency by creating a level of alienation between organizations and the people who made up these organizations. The separation was necessary in order to permit ever-more efficient markets to manage and harness human effort, displacing earlier models based on human relations, long-term loyalty, or efficiency wages. By contrast, a model of motivation that assumes that belonging to a socially-meaningful interaction is critical for engaging the full capacities of people suggests a continued role for firm that can integrate social meaning and relations into their organizational ethos and practice. In other words, here peer production joins diverse lines of research that suggest that "high-road" strategies that invest in building the firm as a collaborative community are preferable to more transactional or efficiency-driven firms, but it suggests further that in the presence of substantially lower transactions costs and competition from nimble, flash organizations and non-market innovation, building communities of meaning around economic collaboration is the primary form of strategic advantage firms have over dynamic, fluid networks of collaborators.

The role of social motivations also reflects more generally on the practice of economic modeling of human behavior. Extensive work in diverse disciplines over the past quarter century has established that human populations exhibit substantial pro-social motivations, and that they respond to a range of non-material, non-self-interested motivations ranging from reciprocity to group identity through, in some cases, altruism (Camerer and Fehr, 2004; Fehr and Gintis, 2007; Ostrom, 1998). Moreover, these motivations are powerful enough to lead subjects consistently to behave in ways that contradict predictions of the standard rational actor model. As the sorry experience of stock option executive compensation schemes has amply demonstrated, the rational actor model can make a poor predictor for the real world effects of major organizational interventions (Bebchuk and Fried, 2006). Finally, extrinsic rewards generally, and monetary rewards in particular, crowd out intrinsic and social rewards, so that any institutional arrangement aimed at optimizing for material rewards will have predictably negative effects on those non-material rewards, whether intrinsic or extrinsic (Bowles and Hwang, 2008; Bowles and Polanía-Reyes, 2012). Once we come to understand that much of human effort directed at exploration and advanced innovation has to be driven in large measure by intrinsic and social motivations when innovation speeds up and uncertainty is high, it becomes clear that both patents and clear firmbased extrinsic rewards can have a negative impact on innovation, and that the most exploratory forms of innovation will need to live outside of firms and market-mediated activities. Organization theory and economics need to learn how to design not better "incentive schemes" as they were traditionally understood, but how to manage competing systems of motivations, that cannot be maximized additively but must instead by balanced and managed culturally so that increases in 
one, relatively easy domain - pay or material reward or punishment—does not undermine intrinsic and socially motivated contributions either within a firm or from complementary efforts on whose innovation a firm depends.

Finally, from a broader institutional analysis perspective, the successful emergence of peer production requires a re-evaluation of the role of property rights as an institutional driver of growth. It is hardly controversial to state that growth depends critically on innovation. Economists have long emphasized the costs of patents, or property-like entitlements, to innovation, given the public goods nature of information goods (Arrow, 1962). The experience of the past twenty five years around the Internet and the World Wide Web has underscored that tension. The success of FOSS in particular underscored that rapid innovation in the software and communications industry has meant that commons-based innovation outpaced proprietary innovation. Free and open-source licensing and open standards optimized the freedom to operate and rapidly experiment, adapt, and implement innovation cycle, rather than focusing on securing appropriation of the benefits of slower moving change. But the role of commons has not been limited to the case of strict public goods. Open spectrum in particular has been the most surprising area where a potentially congestible good has shown more innovation and market adoption when treated as a commons (WiFi and similar bands) than as property (mobile licenses). Across diverse industries from smart grid communications through healthcare to inventory management and even mobile data, spectrum commons, rather than property, has innovated faster and captured larger market share than has proprietary spectrum (Benkler, 2012). More generally (see Benkler, 2013), once one accounts also for public highways and roads, major international shipping ways, as well as common-carrier or public utility infrastructure like electricity or water, the idea that property, as opposed to a mixed infrastructure of property and commons, is the foundation of growth, is due for a major revision.

\section{Declaration of Conflicting Interests}

The author(s) declared no potential conflicts of interest with respect to the research, authorship, and/or publication of this article.

\section{Funding}

The author(s) received no financial support for the research, authorship, and/or publication of this article.

\section{References}

Arrow K (1962) Economic welfare and the allocation of resources for invention. In: Nelson R (ed.) The Rate and Direction of Inventive Activity. Princeton, NJ: Princeton University Press, pp. 609-625.

Baldwin C and Von Hippel E (2010) Modeling a Paradigm Shift: From Producer Innovation to User and Open Collaborative Innovation. Cambridge, MA: MIT Sloan School of Management.

Bebchuk L and Fried J (2006) Pay without Performance: The Unfulfilled Promise of Executive Compensation. Cambridge, MA: Harvard University Press.

Benkler Y (2002) Coase's Penguin, or Linux and the Nature of the Firm. Yale Law Journal 112: 369-446.

Benkler Y (2012) Open wireless versus licensed spectrum: Evidence from market adoption. Harvard Journal of Law and Technology 26: 69-164.

Benkler Y (2013) Commons and growth: The essential role of open commons in market economies. University of Chicago Law Review 80: 1499-1556.

Benner M and Tushman M (2003) Exploitation, exploration, and process management. The Academy of Management Review 28(2): 238-256.

Bessen J (2006) Open source software: Free provision of complex public goods. In: Bitzer J and Schröder PJH (eds) The Economics of Open Source Software Development. Elsevier B.V, pp. 57-82.

Boudreau KJ, Lacetera N and Lakhani KR (2011) Incentives and problem uncertainty in innovation contests: An empirical analysis. Management Science 57: 843-863. 
Bowles S and Hwang SA (2008) Social preferences and public economics: Mechanism design when social preferences depend on incentives. Journal of Public Economics 92: 1811-1820.

Bowles S and Polanía-Reyes S (2012) Economic incentives and social preferences: Substitutes or complements? Journal of Economic Literature 50: 368-425.

Burstein M and Murray F (2016) Innovation prizes in practice and theory. Harvard Journal of Law and Technology 29: 401-453. Available at SSRN: http://ssrn.com/abstract=2741827

Camerer C and Fehr E (2004) Measuring social norms and preferences using experimental games: A guide for social scientists. In: Henrich J, Boyd R, Bowles S, et al. (eds) Foundations of Human Sociality: Economic Experiments and Ethnographic Evidence from Fifteen Small-Scale Societies. Oxford: Oxford University Press, pp. 55-95.

Chesborough H (2003) Open Innovation: The New Imperative for Creating and Profiting from Technology. Cambridge, MA: Harvard Business Press.

Coase R (1937) The nature of the firm. Economica 16: 386-405.

David P and Shapiro J (2008) Community-based production of open source software: What do we know about the developers who participate? Available at: http://ssrn.com/abstract=1286273 (accessed 29 March 2016).

Fehr E and Gintis H (2007) Human motivation and social cooperation: Experimental and analytical foundations. Annual Review of Sociology 33: 43-64.

Ghosh RA (1998) Cooking pot markets: An economic model for the trade in free goods and services on the net. First Monday, 2 March. Available at: http://firstmonday.org/htbin/cgiwrap/bin/ojs/index.php/fm/rt/ printerFriendly/580/501 (accessed 29 March 2016).

Gilson R (1999) The legal infrastructure of high technology industrial districts: Silicon Valley, route 128, and covenants not to compete. New York University Law Review 74: 575-629.

Gilson R, Sabel C and Scott R (2008) Contracting for innovation: Vertical disintegration and interfirm collaboration. Columbia Law Review 109: 431-502.

Gilson R, Sabel C and Scott R (2010) Braiding: The interaction of formal and informal contracting in theory, practice and doctrine. Columbia Law Review 110: 1377-1447.

Hagel J and Seely Brown J (2005) The Only Sustainable Edge: Why Business Strategy Depends on Productive Friction and Dynamic Specialization. Boston, Mass: Harvard Business School Press.

Howe J (2006) Crowdsourcing: Why the Power of the Crowd Is Driving the Future of Business. New York: Three Rivers Press.

Kollock P (1999) The economies of online cooperation: Gifts and public goods in cyberspace. In: Smith M and Kollock P (eds) Communities in Cyberspace. London: Routledge, pp. 220-239.

Lakhani K and Wolf R (2005) Why hackers do what they do: Understanding motivation and effort in free/ open source software projects. In: Feller J, Fitzgerald B, Hassam S, et al. (eds) Perspectives on Free and Open Source Software. Cambridge, MA: The MIT Press, pp. 3-22.

Lakhani K, Lifshitz-Assaf H and Tushman M (2013) Open innovation and firm boundaries: Task decomposition, knowledge distribution and the locus of innovation. In: Grandori A (ed.) Handbook of Economic Organization: Integrating Economic and Organization Theory. Gloucester: Edward Elgar, pp. 355-382.

Landini F (2012) Technology, property rights and organizational diversity in the software industry. Structural Change and Economic Dynamics 23: 137-150.

Lerner J and Tirole J (2002) Some simple economics of open source. Journal of Industrial Economics 50: 197-234.

Moglen E (1999) Anarchism triumphant: Free software and the death of copyright. First Monday, 2 August. Available at: http://firstmonday.org/ojs/index.php/fm/article/view/684/594 (accessed 29 March 2016).

Ostrom E (1990) Governing the Commons: The Evolution of Institutions for Collective Action. Cambridge: Cambridge University Press.

Ostrom E (1998) A behavioral approach to the rational choice theory of collective action. American Political Science Review 92: 1-22.

Powell W (1990) Neither markets nor hierarchy: Network forms of organization. Research in Organizational Behavior 12: 295-336. 
Powell W (1996) Interorganizational collaboration in the biotechnology industry. Journal of Institutional and Theoretical Economics 120: 197-215.

Retelny D, Robaszkiewicz S, To A, et al. (2014) Expert crowdsourcing with flash teams. Available at: http:// hci.stanford.edu/publications/2014/flashteams/flashteams-uist2014.pdf (accessed 28 March 2016).

Saxenian A (2000) Regional Advantage: Culture and Competition in Silicon Valley and Route 128. Cambridge, MA: Harvard University Press.

Von Hippel E (1988) The Sources of Innovation. Oxford: Oxford University Press.

Von Hippel E (2005) Democratizing Innovation. Cambridge, MA: The MIT Press.

Von Hippel E and Von Krogh G (2003) Open source software and the 'private-collective' innovation model: Issues for organization science. Organization Science 14: 209-223.

Williamson E (1985) The Economic Institutions of Capitalism. New York: Free Press; London: Collier Macmillan.

\section{Author biography}

Yochai Benkler is the Jack N. and Lillian R. Berkman Professor of Entrepreneurial Legal Studies at Harvard law School and the Berkman Center for Internet and Society at Harvard University. His work has focused on the role of information commons and decentralized collaboration to innovation, information production, and freedom in the networked economy and society. His articles Coase's Penguin, Or Linux and the Nature of the Firm and Sharing Nicely: On Shareable Goods and the emergence of sharing as a modality of economic production, and his book The Wealth of Networks, How Social Production Transforms Markets and Goods were among the earliest systematic analyses of online collaborative production and the challenges it poses to organization theory. His work can be freely access at http://www.benkler.org. 